\title{
Diskusi Penyusunan RPJMDES Dalam Mewujudkan Desa Tanggap Bencana (Studi Kasus Desa Paku)
}

\author{
Jamaluddin $^{1}$, Muhammad̦ Muthahari Ramadhani ${ }^{2}$, Muhammad Ridho Fauzi ${ }^{3}$, Refina \\ Damayanti Hutagalung , Ati , Muhammad Riswan Yustiwandi ${ }^{6}$, Hayatun Nisa ${ }^{7}$, Kurniawan \\ Hidayat ${ }^{8}$, Tri Utomo Putra \\ ${ }^{12}$ Universitas Lambung Mangkurat, Fakultas Ilmu Sosial dan Ilmu Politik, \\ Jl. H. Hassan Basry, Banjarmasin, Indonesia \\ ${ }^{3456789}$ Mahasiswa Program Studi Ilmu Pemerintahan, Universitas Lambung Mangkurat, Fakultas Ilmu \\ Sosial dan Ilmu Politik, \\ Jl. H. Hassan Basry, Banjarmasin, Indonesia, \\ *email korespondensi : jamaluddin.fisip@ulm.ac.id
}

Diajukan

29 Oktober 2021

\section{Informasi Artike}

Diterima

20 November 2021
Diterbitkan

30 November 2021

\section{Keywords:}

Perencanaan pembangunan desa Desa Tanggap Bencana

Desa Paku

Pengabdian Masyarakat

\begin{abstract}
In development planning, a village must have a plan that can be used as a reference in implementing the development of a village, both in terms of physical and non-physical development. In accordance with Article 4 of Permendagri No. 114/2014, village development plans are prepared in a timeframed manner including: Village Medium-Term Development Plans (RPJM Desa) for a period of 6 years; and the Village Annual Development Plan or the so-called Village Government Work Plan (RKP Desa), is an elaboration of the Village RPJM for a period of 1 (one) year and is stipulated by village regulations. The method used in the preparation of the Paku Village MediumTerm Development Plan to realize a disaster-responsive village is the method of discussion or exchanging ideas between village officials. The initial stage of preparation in the preparation of the Village RPJM to be able to realize a disaster-responsive nail village. The discussion stage for the preparation of the RPJMDes of Paku Village was carried out at the Paku Village Head's Office and assisted by the Head of the RPJMDes Preparation Team, namely Mr. Kusnadiansyah and the Paku Village Head discussing the disaster response village.
\end{abstract}

\begin{abstract}
ABSTRAK
Dalam perencanaan pembangunan suatu desa harus mempunyai sebuah perencanaan yang dapat dipergunakan sebagai sebuah acuan dalam pelaksanaan pembangunan suatu desa baik dari segi pembangunan secara fisik maupun nonfisik. Sesuai pasal 4 Permendagri No 114/2014, perencanaan pembangunan desa disusun secara berjangka meliputi : Rencana Pembangunan Jangka Menengah Desa (RPJM Desa) untuk jangka waktu 6 tahun; dan Rencana Pembangunan Tahunan Desa atau yang disebut Rencana Kerja Pemerintah Desa (RKP Desa), merupakan penjabaran dari RPJM Desa untuk jangka waktu 1 (satu) tahun dan ditetapkan dengan peraturan desa. Metode yang digunakan dalam penyusunan Rencana Pembangunan Jangka Menengah Desa Paku untuk mewujudkan desa tanggap bencana adalah metode diskusi atau bertukar pikiran antara aparatur desa. Tahap awal pada tahapan persiapan dalam penyusunan RPJM Desa untuk dapat mewujudkan desa paku yang tanggap bencana. Tahapan Diskusi Penyusunan RPJMDes Desa Paku dilaksanakan di Kantor Kepala Desa Paku dan didampingi oleh Ketua Tim Penyusunan RPJMDes yaitu Bapak Kusnadiansyah serta Kepala Desa Paku membahas mengenai desa tanggap bencana.
\end{abstract}

\section{Copyright and License:}

Authors retain copyright and grant the journal right of first publication with the work simultaneously licensed under a Creative Commons Attribution 4.0 International License that allows others to share the work with an acknowledgment of the work's authorship and initial publication in this journal. 


\section{PENDAHULUAN}

Dalam perencanaan pembangunan suatu desa harus mempunyai sebuah perencanaan yang dapat dipergunakan sebagai sebuah acuan dalam pelaksanaan pembangunan suatu desa baik dari segi pembangunan secara fisik maupun nonfisik. Pembangunan suatu desa haruslah berkelanjutan sehingga cita-cita yang digaungkan pemerintah untuk membangun dari pinggiran dapat terlaksana. Perencanaan pembangunan desa merupakan proses tahapan kegiatan yang diselenggarakan oleh pemerintah desa dengan melibatkan Badan Permusyawaratan Desa dan unsur masyarakat secara partisipatif guna pemanfaatan dan pengalokasian sumber daya desa dalam rangka mencapai pembangunan desa yang berkelanjutan.

Berdasarkan Perencanaan pembangunan desa merupakan proses tahapan kegiatan yang diselenggarakan oleh pemerintah desa dengan melibatkan Badan Permusyawaratan Desa dan unsur masyarakat secara partispatif guna pemanfaatan dan pengalokasian sumber daya desa dalam rangka mencapai tujuan pembangunan desa yang berkelanjutan.

Dalam rangka upaya peningkatan kualitas hidup dan kehidupan untuk sebesar-besarnya kesejahteraan masyarakat desa sesuai ketentuan umum pasal 1 Permendagri No 114/2014 maka desa harus memiliki rencana pembangunan berjangka dan terukur. Sesuai pasal 4 Permendagri No 114/2014, perencanaan pembangunan desa disusun secara berjangka meliputi : Rencana Pembangunan Jangka Menengah Desa (RPJM Desa) untuk jangka waktu 6 tahun; dan Rencana Pembangunan Tahunan Desa atau yang disebut Rencana Kerja Pemerintah Desa (RKP Desa), merupakan penjabaran dari RPJM Desa untuk jangka waktu 1 (satu) tahun dan ditetapkan dengan peraturan desa. Kemudian diperkuat dalam pasal 115 Peraturan Pemerintah No 43/2014 yang menyebutkan bahwa Perencanaan pembangunan desa menjadi pedoman bagi Pemerintah Desa dalam menyusun rancangan RPJM Desa, RKP Desa dan daftar usulan RKP Desa.

RPJM Desa disusun dengan maksud menyediakan acuan resmi bagi pemerintah desa untuk menyusun Rencana Kerja Pembangunan Desa (RKP Desa), sekaligus merupakan acuan penentuan pilihanpilihan program kegiatan tahunan daerah yang akan dibahas dalam rangkaian Forum Musyawarah Perencanaan Pembangunan Daerah secara berjenjang. Oleh karena itu isi dan substansinya mencakup indikasi rencana program dan kegiatan lintas sumber pembiayaan baik APBD maupun APB Desa termasuk Alokasi Dana Desa (ADD) Dan lain-lain.

Pemerintah pusat melalui Badan Nasional Penanggulangan Bencana (BNPB) telah menyusun sistem dan strategi melalui kebijakan agar upaya PRB berbasis pada komunitas. Strategi tersebut yaitu membentuk Desa Tangguh Bencana (Destana) yang ditulis dalam Peraturan Kepala Badan Penanggulangan Bencana Nasional Nomor 1 Tahun 2012. Dikutip dari Peraturan Kepala BNPB Nomor 1 Tahun 2012, yang dimaksud dengan Desa/Kelurahan Tangguh Bencana adalah desa/kelurahan yang memiliki kemampuan mandiri untuk beradaptasi dan menghadapi ancaman bencana, serta memulihkan diri dengan segera dari dampak bencana yang merugikan, jika terkena bencana.

Desa Tangguh Bencana (Destana) merupakan desa yang memiliki kapasitas untuk mengenali potensi bencana, mengurangi potensi bencana serta mampu mengorganisasi semua elemen dalam masyarakat untuk turut serta berpartisipasi dalam kebencanaan. Adapun bentuk kapasitas yang dimiliki oleh Desa Tangguh Bencana yaitu terwujud dengan adanya perencanaan pembangunan yang didalamnya mengandung berbagai upaya pencegahan dari potensi bencana, kesiapsiagaan serta PRB pasca bencana.

\section{METODE}

Rencana Pembangunan Jangka Menengah Desa (RPJM Desa) adalah dokumen perencanaan desa untuk periode enam tahun yang memuat strategi arah kebijakan pembangunan desa, keuangan desa dan prioritas kewilayahan. RPJM Desa disusun untuk menjadi panduan oleh aparatur desa dalam rangka mengelola potensi dan persoalan desa, sehingga RPJM Desa terintegrasi dengan perencanaan pembangunan kabupaten/kota (PP tentang desa Pasal 63 ayat 1 no 72/2005).

Metode yang digunakan dalam penyusunan Rencana Pembangunan Jangka Menengah Desa Paku untuk mewujudkan desa tanggap bencana adalah metode diskusi atau bertukar pikiran antara aparatur desa. Proses penyusunan dokumen nya harus dilakukan secara hirarkis yang memuat kebijakan program dan kegiatan pembangunan sejalan dengan kehendak masyarakat. Prioritas pembangunan desa paku saat ini adalah pembangunan siring sungai sebagai bentuk upaya tanggap bencana. Pembangunan siring sungai sangat penting karena dapat menjadi pelindung abrasi sungai sehingga dapat terhindar dari bencana seperti banjir. 


\section{HASIL DAN PEMBAHASAN}

RPJM Desa merupakan dokumen milik bersama sebagai acuan kebijakan desa yang disusun secara partisipatif melibatkan pemangku kepentingan. Prinsip musyawarah dan partisipasi menjadi landasan dalam proses penyusunan RPJM Desa yang dilaksanakan secara transparan, akuntabel, dan melibatkan masyarakat dalam pengambilan keputusan perencanaan di semua tahapan perencanaan, mencakup:

a. identifikasi pemangku kepentingan yang perlu dilibatkan dalam proses pengambilan keputusan dalam perencanaan desa;

b. kesetaraan antara pemerintah desa dan pemangku kepentingan lain dalam pengambilan keputusan;

c. transparasi dan akuntabilitas dalam proses perencanaan desa;

d. keterwakilan dari seluruh komponen masyarakat, terutama kelompok perempuan dan kelompok rentan;

e. $\quad$ kepemilikan (sense of ownership) masyarakat terhadap RPJM Desa;

f. pelibatan media dalam sosialisasi RPJM Desa; dan

g. konsensus atau kesepakatan pada semua tahapan penting pengambilan keputusan, seperti: perumusan isu pembangunan desa dan permasalahan, perumusan tujuan, strategi dan kebijakan serta prioritas program

\section{Tahapan Persiapan}

Tahap awal pada tahapan persiapan dalam penyusunan RPJM Desa untuk dapat mewujudkan desa paku yang tanggap bencana adalah sebagai berikut :

a. Mempersiapkan dan mengundang tim peyusun RPJM Desa untuk dapat melakukan kegiatan diskusi penyusunan RPJM Desa dalam mewujudkan Desa Paku yang tanggap bencana. Dalam hal ini tim penyusun RPJM Desa dibina oleh Kepala Desa dan Sekretaris Desa selaku ketua.

b. Disiapkan pula materi Tanggap Bencana yang di dalamnya memuat bentuk ataupun upayaupaya yang dapat dilakukan dalam proses tanggap bencana.

c. Mempersiapkan ruangan dan tempat duduk yang akan ditempati untuk kegiatan diskusi tersebut, dan;

d. Mempersiapkan alat-alat yang dibutuhkan untuk keberlangsungan kegiatan diskusi yaitu laptop dan LCD.

\section{Tahapan Pelaksanaan}

Tahapan Diskusi Penyusunan RPJMDes Desa Paku dilaksanakan di Kantor Kepala Desa Paku dan didampingi oleh Ketua Tim Penyusunan RPJMDes yaitu Bapak Kusnadiansyah serta Kepala Desa Paku membahas mengenai desa tanggap bencana.

Didalam RPJM Desa Paku itu sendiri disusun untuk tahun 2022 s/d 2027. Kepala Desa Paku, Bapak Aspianor mengatakan bahwa Desa Paku tidak pernah mengalami bencana alam yang besar, bencana alam yang pernah dialami oleh Desa Paku hanya banjir yang tidak terlalu besar. Karena itulah dilakukan diskusi Penyusunan RPJMDes ini, agar apabila sewaktu-waktu desa Paku mengalami suatu bencana alam yang lumayan besar dan merusak fasilitas, desa Paku akan lebih tanggap dan apabila bencana alam itu sudah selesai, maka akan lebih cepat dalam membangun kembali fasilitas yang rusak akibat bencana alam tersebut.

Ada Beberapa poin yang di bahas antara lain adalah, Kegiatan Penanggulanggan Bencana, Penanganan Keadaan Darurat, dan Penanganan Kegiatan Mendesak. Untuk Kegiatan Penanggulangan Bencana dianggarkan sekitar Rp. 50.000.000, Penanganan Keadaan Darurat sekitar Rp. 8.882.573, dan untuk Penanganan Keadaan Mendesak sekitar Rp. 4.003.070.

\section{Hasil Kegiatan}

Capaian yang diperoleh dari hasil diskusi ini adalah terbentuknya RPJM Desa yang memuat pembangunan siring sungai dan sarana prasarana lainnya untuk mewujudkan desa tanggap bencana 


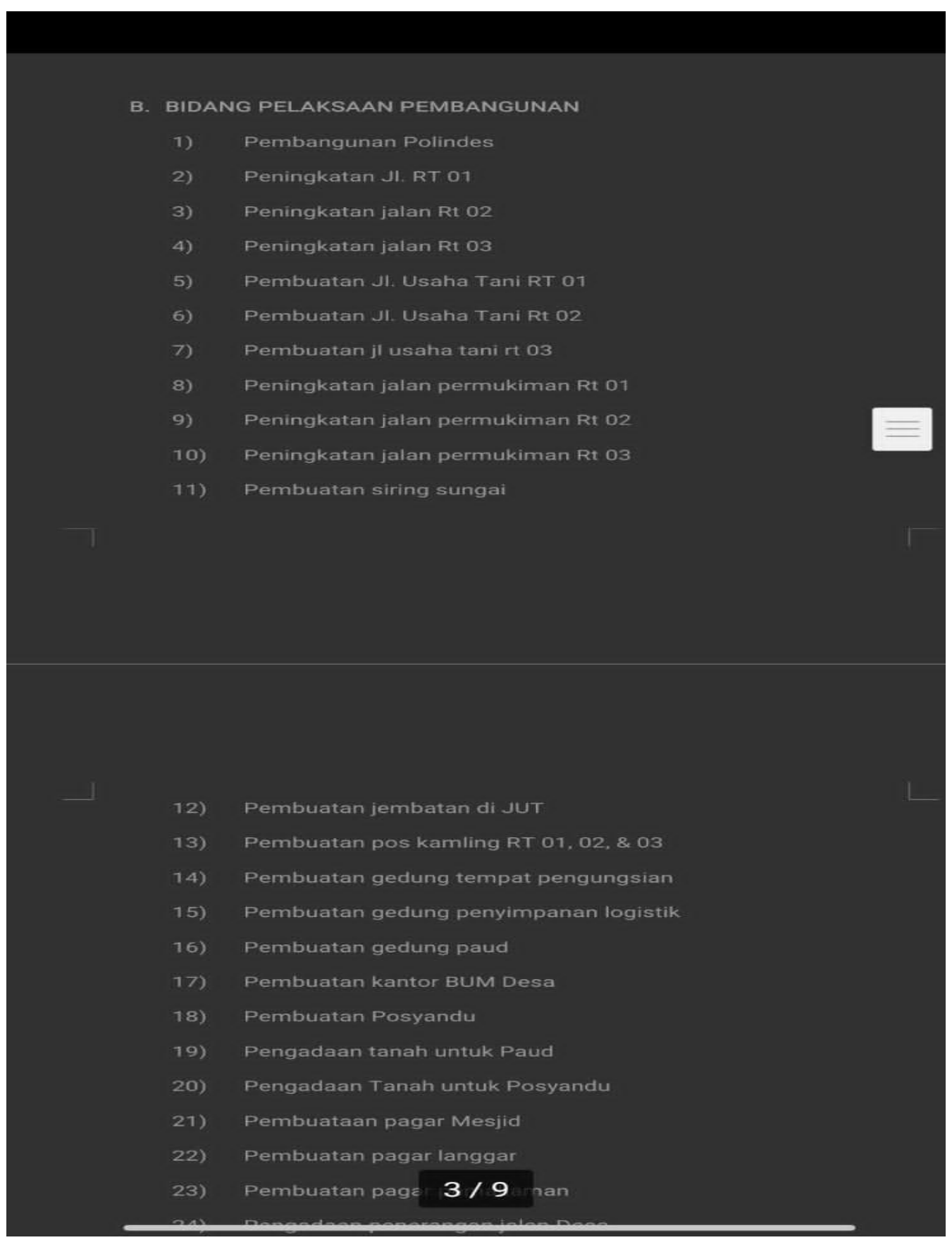

Gambar 1. Daftar Rencana Pembangunan Sarana dan Prasarana di Desa Paku 


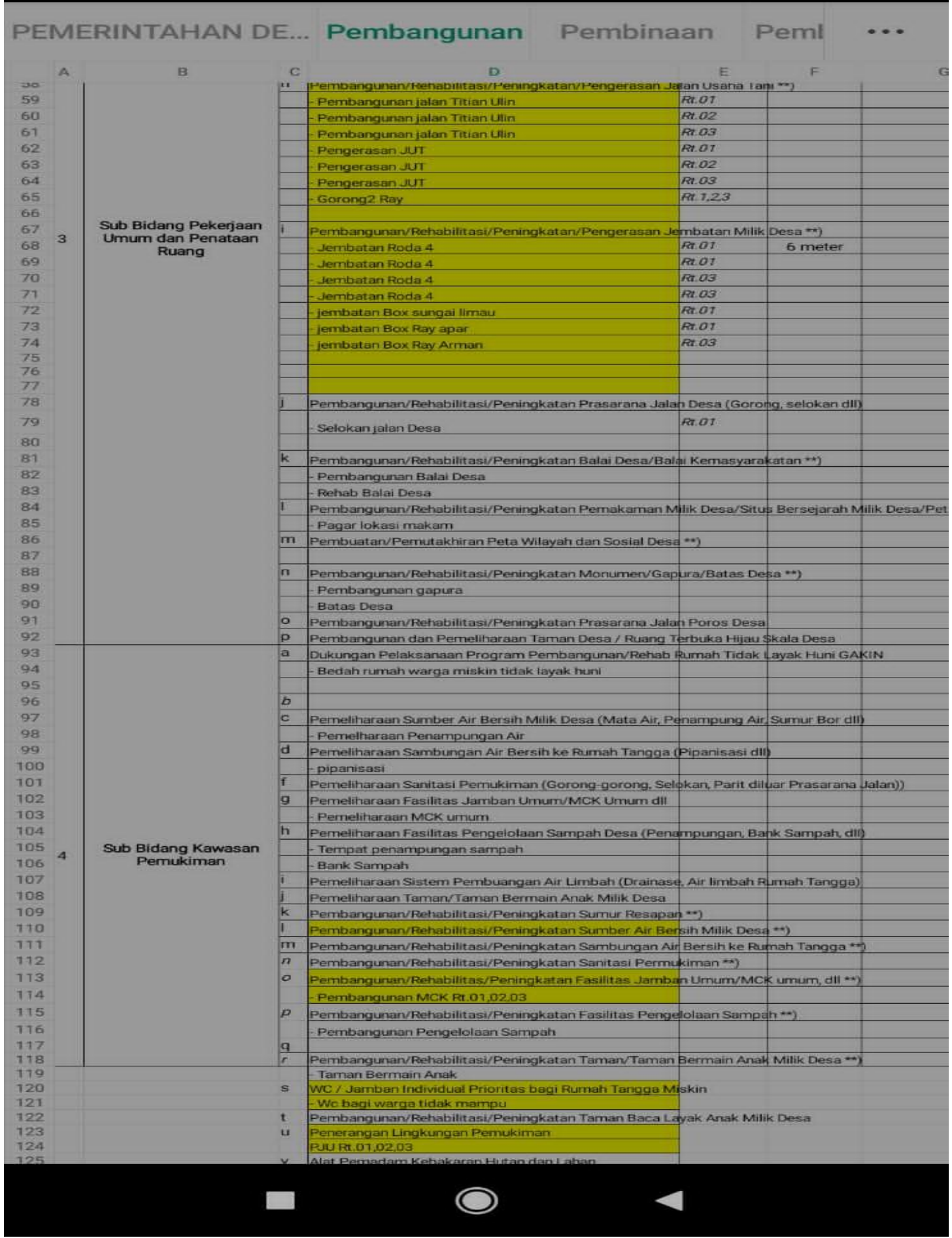

Gambar 2. Daftar Rencana Pembangunan Sarana dan Prasarana di Desa Paku 


\section{KESIMPULAN}

(1) Tahap awal pada tahapan adalah mempersiapkan dan mengundang tim peyusun RPJM Desa untuk dapat melakukan kegiatan diskusi penyusunan RPJM Desa, Disiapkan pula materi Tanggap Bencana.

(2) Desa Paku tidak pernah mengalami bencana alam yang besar, karena itulah dilakukan diskusi Penyusunan RPJMDes agar lebih cepat dalam membangun kembali fasilitas yang rusak akibat bencana alam tersebut.

(3) Untuk Kegiatan Penanggulangan Bencana dianggarkan sekitar Rp. 50.000.000, Penanganan Keadaan Darurat sekitar Rp. 8.882.573, dan untuk Penanganan Keadaan Mendesak sekitar Rp. 4.003.070.

(4) Keterangan Daftar Rencana Pembangunan Sarana dan Prasarana diberikan langsung oleh Kepala Desa Paku.

\section{UCAPAN TERIMA KASIH}

Ucpan terima kasih disampaikan kepada FISIP Universitas Lambung Mangkurat yang telah mendukug terlaksananya kegiatan ini.

\section{REFERENSI}

Permendagri No 114 tahun 2014 Tentang Pedoman Pembangunan Desa

Peraturan Pemerintah No 43 Tahun 2014 Tentang Peraturan Pelaksanaan Undang-Undang No 6 Tahun 2014 Tentang Desa

Peraturan Pemerintah No 72 Tahun 2005 Tentang Pemerintah Desa

Sutopo dan Dwi Tiyanto, "Pentingnya RPJM DesaDalam Memperlancar Pelaksanaan Undang-Undang No. 6 Tahun 2014 Tentang Desa”, Journal Of Rural and Development, 2014, 1:118.

.Julis, Admiral Musa, dkk. 2020. Jurnal Swabumi, Vol 8 . 